\title{
“Os Cansaços e Golpes da Vida”: Os Sentidos do Envelhecimento e Demandas em Saúde entre Idosos do Quilombo Rincão do Couro, Rio Grande do Sul
}

\author{
Elisângela Domingues Severo Lopes ${ }^{1}$ \\ ${ }^{1}$ Universidade Federal do Rio Grande, RS Brasil. \\ Cassiane de Freitas Paixão ${ }^{2}$ \\ ${ }^{2}$ Universidade Federal do Rio Grande, RS Brasil. \\ Daniela Barsotti Santos ${ }^{3}$ \\ ${ }^{3}$ Universidade Federal do Rio Grande, RS, Brasil.
}

Resumo: A presente pesquisa foi realizada em uma comunidade tradicional denominada Quilombo Rincão do Couro, no Rio Grande do Sul. Neste quilombo, vivem aproximadamente 30 famílias descendentes de pessoas negras que foram escravizadas. $\mathrm{O}$ objetivo da pesquisa foi compreender os sentidos sobre o envelhecimento que são produzidos nas narrativas de idosos habitantes desta comunidade e identificar ações e estratégias usadas por eles na promoção da saúde no local. A pesquisa qualitativa, teve participação de seis idosos, comidades entre 61 e 83 anos, que responderam a uma entrevista com roteiro semiestruturado. As entrevistas foram audiogravadas e transcritas em sua íntegra, constituindo no corpus de análise. O material obtido foi analisado por meio da elaboração de árvores de associação de ideias que geraram dois eixos temáticos: 1. Os sentidos do envelhecimento: a idade cronológica, a solidão, os acontecimentos da vida, a perda das funções do corpo e o adoecimento; 2. Práticas para a obtenção da saúde: cuidados com a saúde por meio do comparecimento às consultas médicas, realização do tratamento prescrito e medicação; ações de promoção de saúde que envolvem alimentação, caminhadas e atividades do cotidiano que são praticadas no decorrer de sua história. Os entrevistados enfatizam a necessidade de uma Unidade Básica Saúde da Família Quilombola local, e os achados desta pesquisa destacam a necessidade de se desenvolver trabalhos e pesquisas da Psicologia em comunidades tradicionais.

Palavras-chave: Saúde Quilombola, Envelhecimento, Psicologia Social, Promoção de saúde.

\section{"The Tiredness and Blows of Life": The Meanings of Aging and Health Demands among Elderly in Quilombo Rincão do Couro, Rio Grande do Sul}

Abstract: This research was carried out in a traditional community called Quilombo Rincão do Couro, in Rio Grande do Sul. Approximately 30 families descended from black people who were enslaved live in this community. The research objective was to understand the meanings about aging produced by the narratives of elderly community's inhabitants and to identify the actions and strategies used by them for local health promotion. The qualitative research had the participation of six elderly people, aged between 61 and 83 years old. They answered an interview with semi-structured script. The interviews were audiographed and transcribed in their entirety, constituting the corpus of analysis. The meanings obtained by association trees of ideas were analysed and generated two thematic axes: 1. Aging senses: the chronological age, solitude, life's events, loss of body functions and illness; 2. Practices for obtaining health: health care through attendance at medical appointments, completion of prescribed treatment and medication; health promotion actions that involve food, hiking and daily activities that are practiced throughout the quilombolas' community history. The interviewees emphasize the need for a local primary health care unit for the local quilombolas' family. This research findings highlighted the need to develop psychology research and studies in traditional communities.

Keywords: Quilombola Health, Aging, Social Psychology, Health Promotion. 


\title{
“Los Cansancios y Golpes de la Vida": Los Sentidos del Envejecimiento y Demandas en Salud entre Ancianos del Quilombo Rincão do Couro, Rio Grande do Sul
}

\begin{abstract}
Resumen: La presente investigación se realizó en una comunidad tradicional denominada Quilombo Rincón del Cuero, en Rio Grande do Sul. En este quilombo, viven aproximadamente 30 familias descendientes de personas negras que fueron esclavizadas. El objetivo de la investigación fue comprender los sentidos sobre el envejecimiento que se producen en las narrativas de ancianos habitantes de esta comunidad e identificar acciones y estrategias usadas por ellos en la promoción de la salud en el lugar. La investigación cualitativa, tuvo participación de seis ancianos, con edades entre 61 y 83 años, que respondieron a una entrevista con un itinerario semiestructurado. Las entrevistas fueron audiogravadas y transcritas en su totalidad, constituyéndose en el corpus de análisis. El material obtenido fue analizado por medio de la elaboración de árboles de asociación de ideas que generaron dos ejes temáticos: 1 . Los sentidos del envejecimiento: la edad cronológica, la soledad, los acontecimientos de la vida, la pérdida de las funciones del cuerpo y la enfermedad; 2. Prácticas para la obtención de la salud: cuidados de la salud a través de la asistencia a las consultas médicas, la realización del tratamiento prescrito y la medicación; acciones de promoción de salud que involucran alimentación, caminatas y actividades de lo cotidiano que se practican en el transcurso de su historia. Los entrevistados enfatizan la necesidad de una Unidad Básica Salud de la Familia Quilombola local, y los hallazgos de esta investigación destacan la necesidad de desarrollar trabajos e investigaciones de la psicología en comunidades tradicionales.

Palabras clave: Salud Quilombola, Envejecimiento, Psicologia Social, Promoción de la Salud.
\end{abstract}

\section{Mulher negra quilombola psicóloga (Introdução) ${ }^{\mathbf{1}}$}

Em algumas Universidades brasileiras, é possível se perceber o recente ingresso de estudantes oriundos de Comunidades Tradicionais Quilombolas². Como também, observa-se a ausência de disciplinas com temáticas que abordem as vivências e historicidade dessas Comunidades. Nesse sentido posso destacar a Universidade Federal do Rio Grande (FURG), em específico o Curso de Psicologia que tem ofertado a disciplina "Psicologia Transcultural" ${ }^{3}$ que, segundo Gentini (2016, p. 74), "teria como âmago o que faz a profunda riqueza deste País: [...] miscigenação cultural, as diferenças de pensamentos, emoções, maneiras de viver e de sentir, de viver a natureza e os processos sociais".
Mesmo podendo contar com essa disciplina, foi possível perceber, enquanto mulher negra quilombola, a deficiência de conteúdos sobre questões e aspectos psicológicos específicos dessa população, e que poderiam ser discutidos em outras disciplinas. Uma das estratégias utilizadas por mim foi a produção dos trabalhos acadêmicos como forma de aproximação entre as Comunidades Quilombolas e a academia. Com a busca pela integração de assuntos da Psicologia com as vivências do quilombo, no sentido de dar voz e visibilidade aos Povos Quilombolas tão sofridos e oprimidos perante a nossa sociedade. Como também uma forma de reafirmar perante o meio acadêmico a minha identidade e pertencimento enquanto quilombola.

\footnotetext{
${ }^{1}$ Artigo derivado do Trabalho de Conclusão do Curso de Psicologia "Os sentidos do envelhecimento para os idosos moradores do Quilombo Rincão do Couro no interior do Rio Grande do Sul”, da Universidade Federal do Rio Grande, 2018.

${ }^{2}$ Programa de Ações Afirmativas da Universidade Federal do Rio Grande (PROAAf-FURG) direcionado às Comunidades Quilombolas (Lopes, 2016b).

${ }^{1}$ Agradecemos ao Professor Doutor Alfredo Guillermo Martin Gentini, idealizador da disciplina “Psicologia Transcultural” por sua generosa contribuição com sugestões para esta pesquisa.
} 
Ser quilombola representa um sinal de luta e resistência (Nascentes, Silva, Soares, Pinto, Westphal, Lopes, 2016). Perceber o sofrimento dos Povos de Comunidades Tradicionais é reconhecer que o mesmo está muito além do castigo físico. Com o decorrer de um pouco mais de um século após a abolição, o sofrimento psíquico ainda está presente como reflexo dos danos causados pela escravidão, e este sofrimento sentido pelos nossos ancestrais continua sendo vivenciado de geração em geração.

Essas são questões que me levam a escrever esse trabalho em primeira pessoa, potencializando a fala das Comunidades Tradicionais e dinamizando isso nas escritas, compreendendo assim alguns aspectos psicológicos desses povos. Destaco a carência que se tem de psicólogas preparadas para atender essa população. Indo mais além, a necessidade da formação de psicólogos quilombolas para atuarem junto das Comunidades.

As vozes que reverberam neste estudo incluem as das demais autoras. Mulheres, pesquisadoras, uma negra socióloga e uma branca psicóloga, que me apoiaram nessa jornada com o desafio de participar na condução de uma pesquisa e subsequente escrita deste artigo que aliasse os Saberes Tradicionais Quilombolas em diálogo com a produção de sentidos, como parte da Psicologia Social da saúde.

O conceito sentido o qual refiro é compreendido enquanto construção social, coletiva, interativa, a qual "as pessoas - na dinâmica das relações sociais historicamente datadas e culturalmente localizadas constroem os termos a partir dos quais compreendem e lidam com as situações e fenômenos a sua volta" (Spink, \& Medrado, 2013, p. 41). Segundo Spink e Menegon (2013) dar sentido ao mundo é uma prática social, sendo o cotidiano permeado por práticas discursivas constituídas por múltiplas vozes. As ideias, as categorias eleitas para expressá-las, bem como os conceitos formalizados são constituídos por âmbitos diversos como os da religião, da arte, da filosofia e da ciência, que também incluem os grupos os quais pertencemos (família, quilombo, o meio acadêmico, a profissão Psicologia, entre outros exemplos) e a mídia (Spink \& Menegon, 2013).

O interesse por fazer esta pesquisa com idosos se deu pelo fato de o Quilombo Rincão do Couro o qual pertenço ter um número expressivo de idosos e pelo intuito de valorizar nossos povos e ancestrais, dando voz e vez a um povo sofrido que ainda vive de certa forma invisível perante a sociedade brasileira. Ao compartilhar este texto, eu torno público as necessidades cotidianas de prevenção de doenças, promoção de saúde e bem-estar dessa população; bem como as reivindicações dos idosos do Quilombo referentes ao acesso às políticas públicas básicas enquanto cidadãos de direitos.

O envelhecimento recebe diferentes significações sociais que são perpassadas pela cultura, produzindo diversos sentidos individuais. Dentre as significações sociais, as conceituações sobre o que é ser idoso e o que é envelhecimento ganham um caráter multidimensional sustentado pelas leis e teorias sobre o envelhecer. Segundo o Estatuto do Idoso, Lei no 10.741, de $1^{\circ}$ de outubro de 2003, é considerada idosa aquela pessoa com idade igual ou acima de 60 anos. Sendo o envelhecimento entendido como um fenômeno natural, irreversível e mundial (Brasil, 2010).

Ao nascimento se tem o início do envelhecimento que termina com a morte, sendo um processo evolutivo contínuo e ininterrupto. Enquanto conceito multidimensional, pode-se considerar como três elementos básicos a idade cronológica, as mudanças biológicas (morfológicas, fisiológicas e bioquímicas) e a atribuição pessoal e subjetiva que nem sempre seguem na mesma direção (Costa, 1998). Acrescida a esta definição, podem ser consideradas outras dimensões como as funcionais, mentais e de saúde que participam da "determinação de quem seja idoso" (Santos, 2010, p. 1036). Ou ainda, tal conceito pode ser descrito enquanto processo que envolve também modificações psicológicas frente a um processo de adaptação cotidiano; e de mudanças sociais como a aposentadoria por exemplo (Santos, 2010).

Moreira e Nogueira (2008) descreveram o envelhecimento como sendo um fenômeno biológico, social e cultural. Nesta definição, envelhecer pode apresentar diversas características de acordo com a cultura, considerando o tempo e espaço; perpassando as trajetórias da vida individual, social e cultural. Sendo assim, entende-se que o envelhecimento ultrapassa as mudanças biológicas, psicológicas e sociais, ao apresentar marcas indicadas pela condição social, cultural, econômica e sanitárias do indivíduo ou da comunidade. As autoras ainda consideraram como implicações dessa experiência contemporânea:

o entrelaçamento do entorno sociocultural em que essa experiência se dá com suas determi- 
nações históricas. Nesse contexto, inúmeras são as ocorrências [sociais, culturais, políticas e econômicas] que influenciam o estilo de vida, os valores e padrões sociais e, consequentemente, os modos de ser do homem e as estruturas psíquicas que se produzem. Incerteza, turbulência, mudanças contínuas, explosão tecnológica, globalização constituem a atualidade e exigem novas e rápidas respostas nos planos individual e coletivo (Moreira, \& Nogueira, 2008, pp. 60-61, grifo do autor).

Considera-se com as mudanças sociais são estabelecidos novos modelos identitários relacionados ao envelhecimento. $\mathrm{O}$ surgimento de novas condutas, hábitos, crenças e imagens compartilhadas socialmente tem modificado de maneira significativa as concepções que tradicionalmente eram relacionadas às "etapas mais tardias da vida". Neste novo modelo identitário se tem o estímulo à atividade, à aprendizagem, à flexibilidade, ao aumento da satisfação pessoal e à constituição de vínculos afetivos inéditos. Essas características seriam parte de uma "nova sensibilidade" que passam a fazer parte do envelhecimento (Silva, 2008).

Com o aumento da população idosa, se tem um desafio à Saúde Pública quando se considera a dificuldade de adequação dos dispositivos de saúde frente a esta nova demanda, seja em seus aspectos estruturais e tecnológicos, seja com relação à formação de profissionais qualificados para trabalhar com idosos (Brito, Freitas, Mesquita, \& Lima, 2013).

Esta questão se torna ainda mais premente quando se pensa na situação dos idosos quilombolas. No Brasil, a Fundação Cultural Palmares (FCP) identificou a existência de 3.271 Comunidades Remanescentes de Quilombos (CRQ), sendo que destas 2.729 foram certificadas pela mesma. No Rio Grande do Sul foram identificadas até o momento 133 comunidades, sendo certificadas 132. Destas, oito ficam localizadas no município de Piratini, sendo umas delas a CRQ Rincão do Couro, todas certificadas pela FCP (2019). Em termos geográficos a sede do Quilombo Rincão do Couro, fica a 40 quilômetros de distância da sede do município de Piratini, e $345 \mathrm{~km}$ de distância da capital Porto Alegre.

Estima-se que a existência do Rincão do Couro seja de 200 anos. Seu nome originou-se de um antigo local - a casa do couro - que primava como atividade produtiva carnear o gado e beneficiar o couro (CAPA, 2010). O reconhecimento do Quilombo Rincão do Couro foi obtido por meio da Portaria de certificação $n^{\circ} 59 / 2010$, com base no Decreto no 4.887 , de 20 de novembro de 2003, que regula o procedimento para identificação, reconhecimento, delimitação, demarcação e titulação das terras ocupadas por remanescentes das comunidades dos quilombos de que trata o art. 68 do Ato das Disposições Constitucionais Transitórias. Desde então, a forma de organização do quilombo se dá através da criação de uma associação comunitária quilombola sem fins lucrativos.

Para a Fundação Cultural Palmares, os quilombolas descendem de africanos que foram escravizados; e que preservam suas tradições culturais, práticas de subsistência e religiosas ao longo dos séculos (FCP, 2019). As comunidades de quilombolas foram constituídas por uma enorme diversidade de processos, que superam a visão de que suas origens seriam apenas ocasionadas a partir "das fugas" acompanhadas da ocupação de terras livres e isoladas. A constituição dos quilombos também se deu pela obtenção das terras pelas heranças, doações, como pagamento de serviços prestados ao Estado, bem como pela permanência dos grupos que continuaram a servir de mão de obra no interior das grandes propriedades, além da compra de terras durante a vigência do sistema escravocrata e mesmo após a sua extinção (Bennett, 2010).

Em tempos difíceis de resistência, o Quilombo busca manter alguns costumes e tradições que lhes foram ensinados e passados pelos seus ancestrais, com intuito de preservar e manter viva a cultura quilombola, como também transmitir esses conhecimentos as futuras gerações. São características comuns desta Comunidade a criação de animais, o plantio de alimentos para consumo próprio, o consumo de comidas típicas quilombolas, a religiosidade, assim como a prática de saberes tradicionais, através do uso de ervas medicinais para tratar algumas enfermidades, $\mathrm{e}$ as benzedeiras que, por meio de suas benzeduras e de sua fé, trazem a cura e o alívio da dor.

As benzeduras são rezadas em voz baixa, usando apenas alguns elementos da natureza como suporte em busca da cura. Para Lopes (2016a), esse saber tradicional é passado através da oralidade das benzedeiras que mesmo mantendo a prática presente atualmente, possui seu número de praticantes diminuindo ao passar do tempo. Segundo Mendes e Cavas (2017, p. 4), 
"às práticas tradicionais empregadas pelas benzedeiras e benzedeiros quilombolas, na promoção da cura e proteção, alia-se uma religiosidade sincrética pelas influências culturais das matrizes africanas, católicas e indígenas".

O idoso tem um lugar de destaque dentro das Comunidades Tradicionais Quilombolas. Por meio dos mais velhos é que são transmitidos os conhecimentos que foram passados a eles pelos nossos ancestrais. Para além das experiências e vivências durante os anos de vida adquiridos pelos idosos, é através deles que os costumes e tradições continuam sendo passados adiante. São com os mais velhos que se aprendem os saberes tradicionais, de como lidar e cultivar a terra, cuidar dos animais, preparar os alimentos típicos da nossa cultura, as rezas, as benzeduras e como manipular as ervas medicinais.

Nesse aspecto, é preciso que os mais novos estejam atentos, ouvindo e observando os mais velhos praticando os saberes. E tudo isso acontece através da oralidade, seja numa roda de conversa, quando a comunidade se reúne, seja no âmbito do lar junto de amigos e familiares. A partir da narrativa dos idosos trabalhei com uma memória individual e coletiva, fazendo com que a comunidade passe a ter conhecimento de como nossos ancestrais viveram e trabalharam para o sustento de suas famílias, permitindo hoje a nossa existência e identidade enquanto descendentes de pessoas negras escravizadas.

Sendo evidente que existem dificuldades de adequação de serviços de saúde na atenção dos idosos, no que se refere a comunidades quilombolas torna-se mais difícil ainda. São poucos os estudos feitos nos quilombos, abordando a temática do envelhecimento quilombola. E boa parte desses estudos apontam a falta de políticas públicas, ações e intervenções relacionados a saúde dos idosos quilombolas.

De acordo, com Oliveira, Pereira, Guimarães e Caldeira (2015), apesar dos avanços para o desenvolvimento da Atenção Primária à Saúde (APS), com a expansão de equipes da Estratégia de Saúde da Família (ESF), não se tem percebido o alcance significativo a esse grupo populacional. Grande parte das comunidades quilombolas, se localizam nas áreas rurais distantes das áreas urbanas, fato que acaba gerando um desconhecimento sobre o "processo saúde-doença" e as condições de saúde dos idosos quilombolas.
As comunidades quilombolas ainda preservam e praticam culturas e conhecimentos que foram trazidos e passados pelos seus ancestrais. Aragão (2014), enfatiza que se torna necessária a compreensão de três aspectos em relação à saúde da população negra:

o político que discute a influência do racismo nas condições de vida e saúde da população negra; a ciência que deve incorporar os sistemas de matriz africana, seus principais elementos em saúde, a preservação da memória cultural, adaptar e (re) criar técnicas de alívio e cura (como uso de plantas, animais e minerais), modelos de diagnósticos (consultas a búzios, cartas, santos e orixás), rezas, cânticos, danças, culinária, e comunidade e existência (axé, expressões dinâmicas da força); e por último a cultura africana que influencia suas visões de mundo e práticas de saúde (Aragão, 2014, pp. 39-40).

Em relação a ausência das políticas públicas Takahashi e Alves (2015, p. 579), afirmam que na falta de ações políticas, como ocorre nas comunidades quilombolas, os idosos "não se veem com perspectivas e se apegam à família, à natureza, à fé e à religiosidade". Ainda nessa questão, os autores questionam: "Essa falta de políticas públicas, em pleno século XXI, [...] mostra que há uma acomodação e uma estagnação diante a vida. O que mais causa dor em um cidadão idoso e negro: a chibata na carne dos seus ancestrais ou a ausência das políticas públicas que desrespeita o direito universal à vida?" (Takahashi, \& Alves, 2015, p. 582).

Quando se considera a atuação da Psicologia nas Comunidades Tradicionais Quilombolas, um estudo realizado por Gonçalves e Fernandes (2017) apontou que pouco se fez para se promover pesquisas e práticas. Este cenário tem se modificado nas últimas décadas devido ao fomento das políticas públicas direcionadas aos territórios tradicionais, como também pela ampliação da participação de psicólogos em municípios de pequeno e médio porte.

Apesar de se presenciar muitos avanços no que se refere ao reconhecimento de direitos dos Povos Tradicionais, atualmente, estamos vivenciando um triste cenário brasileiro em relação ao desmonte destes direitos. E é, nesta perspectiva que Carvalho e Macedo (2018) apontam os desafios da Psicologia 
nos dias atuais, sendo um deles a tentativa de aproximação entre os segmentos governamentais e do agronegócio das Comunidades Tradicionais. Desta forma a "[...] Psicologia estaria contribuindo para a promoção da qualidade de vida e o combate das desigualdades [...]". Então seria preciso refletir acerca da atuação profissional e a formação em Psicologia, para que haja qualificação técnica e ética que compreendam o modo de viver das Comunidades Tradicionais e as suas singularidades. Do ponto de vista dos autores se faz necessário que o psicólogo atue no "exercício ético-político da profissão em defesa da garantia de direitos e emancipação humana" dos Povos e Comunidades Tradicionais.

Em 2018 o Conselho Regional de Psicologia do Rio Grande do Sul (CRPRS) realizou o Encontro Preparatório da Rede de Articulação Psicologia, Povos Indígenas, Quilombolas, de Terreiro, Tradicionais e em Luta por Território em Porto Alegre-RS que antecedeu ao "I Encontro Nacional de Rede de Articulação Psicologia, Povos”, Guararema-SP. Os eventos foram realizados com o propósito de refletir sobre a atuação da Psicologia nas Comunidades Tradicionais. A Rede de Articulação visa construir para a comunicação entre profissionais e lideranças das Comunidades, assim como orientar psicólogas e a sociedade sobre as especificidades culturais dos Povos tradicionais.

Embora seja recente o contato da Psicologia com temática dos Povos Tradicionais, a mesma tem muito a contribuir e aprender com a diversidade de cultura, subjetividade e imaginário destas populações. Esta pesquisa teve por objetivo compreender os sentidos sobre o envelhecimento que são produzidos nas narrativas de idosos habitantes desta comunidade e identificar ações e estratégias usadas por eles na promoção da saúde no local.

\section{Uma perspectiva metodológica quilombola no contexto diálogo (Método)}

Este estudo, de abordagem qualitativa, baseou-se no referencial teórico da Psicologia Social da Saúde ou da Psicologia Social aplicada à Saúde. Entende-se que a atuação profissional e a pesquisa em Psicologia Social da Saúde são caracterizadas pelo compromisso com os direitos sociais, dialogando com teorias e autores preocupados com os modos de viver e de organizar a sociedade brasileira contemporânea; "transitando dos microprocessos de produção de sen- tidos às questões institucionais e políticas" (Spink, 2011, p. 27).

A pesquisa qualitativa em Psicologia enfoca o conhecimento sobre a subjetividade, considerando que a história e o contexto marcam a sua singularidade (Rey, 2002). De acordo com Flick (2013), em uma pesquisa que utiliza uma abordagem qualitativa, os pesquisadores costumam utilizar como ferramenta de trabalho as narrativas que relatam trajetórias biográficas ou discursos dos entrevistados. Neste estudo, optou-se por adotar uma postura construcionista social com a análise da produção de sentidos, entendida como prática social dialógica que envolve a linguagem em uso (Spink, \& Medrado, 2013).

A definição do Estatuto do Idoso, Lei no 10.741, de $1^{\circ}$ de outubro de 2003 , foi adotada para se convidar como participantes do estudo seis idosos quilombolas com idade igual ou superior a 60 anos. Todos assinaram o Termo de Consentimento Livre e Esclarecido, conforme a Resolução no 466/ 12 do Conselho Nacional de Saúde do Ministério da Saúde, sendo a pesquisa aprovada pelo Comitê de Ética em Pesquisa na Área da Saúde (Cepas) da FURG, Parecer no 144/2018.

As falas foram obtidas por meio da realização de entrevistas, com roteiro semiestruturado, realizadas individualmente com o auxílio de um gravador em dias e horários pré-estabelecidos com cada participante em sua residência. O roteiro semiestruturado continha questões que caracterizavam os participantes como idade, sexo, religião, estado conjugal e pessoas com quem coabitam; além de cinco questões abertas que contemplaram como temas o envelhecimento, o sentido do envelhecer, os cuidados com a própria saúde, ações de prevenção e promoção de saúde, e conhecimentos sobre ações em saúde no quilombo.

As entrevistas foram transcritas integralmente para posteriormente serem realizadas leituras constantes a fim de se conhecer as relações estabelecidas pelos entrevistados acerca das temáticas abordadas, e para definição de uma estratégia de sistematização, análise e interpretação dos dados. Iniciou-se a análise das transcrições por meio da elaboração de árvores de associações de ideias. De acordo com Spink, tal recurso pode ser utilizado para compreensão de como um determinado argumento é construído visando a produção de sentido em contexto dialógico. As árvores de associação de ideias permitem visualizar o fluxo conversacional a partir da questão colocada pelo 
entrevistado; possibilitando entender "as singularidades da produção de sentido, presas tanto à história de cada pessoa quanto à dialogia intrínseca do processo de entrevista" (Spink, \& Lima, 2013, p. 114-115).

Também foram realizadas anotações sobre as impressões e questionamentos da pesquisadora em um diário de pesquisa com o intuito de auxiliar no processo de análise e interpretação das entrevistas.

\section{Caminho pelo bosque do Quilombo Rincão do Couro (Resultados)}

Ao iniciar a montagem e o desenho das árvores de associação de ideias para cada entrevista transcrita, logo fui remetida à imagem de um bosque como parte do Quilombo Rincão do Couro. Com essa metáfora em mente e com o intuito de se preservar a identidade dos participantes, foi atribuído a cada idoso o nome de uma espécie de árvore significativa para os membros da comunidade quilombola: Goiabeira-do-mato, Araçá-amarelo, Cambará, Corticeira, Pitangueira e Coronilha.

As árvores Goiabeira-do-mato, Araçá-amarelo e a Pitangueira costumam a dar frutos que são comumente coletados nas matas pelas famílias quilombolas para o consumo próprio. A madeira de Cambará é muito utilizada na construção de cercas e aramados, como também, na construção das casas e galpões. Já a Corticeira tem o tronco utilizado para confeccionar pilões, gamelas e bancos. A árvore Coronilha, assim como as outras espécies citadas anteriormente, tem suas folhas utilizadas no quilombo na preparação de chás. Além disso, esta última tem um significado especial para os habitantes do Quilombo Rincão do Couro, pelo fato de as primeiras reuniões comunitárias de organização para a obtenção da certificação quilombola aconteceram em torno de uma Coronilha que propiciou ao coletivo desfrutar da sombra produzida por sua copa e folhagens, seguindo uma antiga tradição.

Atualmente vivem no quilombo aproximadamente 30 famílias, sendo a fonte de renda principal dos idosos advinda da aposentadoria rural. Dos idosos participantes do estudo, quatro são do gênero feminino e dois do gênero masculino, com as idades entre 61 e 83 anos. Com relação ao estado marital, três idosas são viúvas e os demais entrevistados são casados. Três idosos(as) declararam morar com cônjuge e filhos(as), duas participantes declararam morar com os filhos(as), e uma entrevistada declarou morar sozinha e todos denominaram-se católicos.

Foram elaboradas árvores de associação das ideias elencadas por entrevistado sobre os significados e sentidos do envelhecimento, bem como prevenção e promoção de saúde para o idoso, como mostra a Figura.

Para Araçá-amarelo, velho seria aquele que tem mais de 80 anos e, para envelhecer, é preciso ter coragem e a ajuda de Deus para continuar vivendo. No que se refere aos saberes religiosos, no Quilombo Rincão do Couro é predominante a religião católica. Sendo comum entre os idosos a Fé em Deus e o culto aos santos católicos, assim como o respeito aos feriados religiosos na comunidade. Alguns dos participantes acreditam que a crença em Deus os ajuda a superar algumas dificuldades do envelhecimento, e, é através desta fé que eles atribuem a "força e coragem" para realizar as tarefas diárias como relatou Araçá Amarelo, fazendo com que consigam vencer "os cansaços e golpes da vida" como mencionou Coronilha. Araçá Amarelo reconhecia-se como uma pessoa idosa, considerando o envelhecer um período difícil de ser vivenciado.

Com relação aos cuidados com a saúde e sua promoção, o participante Araçá Amarelo considerou importante ir consultar-se com o médico, além de manter suas atividades laborais como estar sempre trabalhando na agricultura e desempenhando atividades como lavrar, plantar, roçar, capinar, cortar lenha e cuidar dos animais. Também relatou realizar caminhadas para ir nos vizinhos e trabalhar. A fala desse

\begin{tabular}{|ll|}
\hline \multirow{2}{*}{ Envelhecimento } & $\begin{array}{l}\text { Ficar velho } \\
\text { Ter mais de } 80 \text { anos } \\
\text { Ter coragem } \\
\text { Ter ajuda de Deus }\end{array}$ \\
Os sentidos do envelhecimento \\
\\
Saúde & $\begin{array}{l}\text { Ir ao médico } \\
\text { Trabalhar } \\
\text { Caminhada }\end{array}$ \\
& \\
\hline
\end{tabular}

Figura

Os sentidos do envelhecimento para árvore Araçá-amarelo. 
participante denota a preocupação com o declínio da força física que possibilita sua subsistência, uma vez que afirma ser preciso ter coragem para envelhecer. Nesse aspecto, a pessoa ao envelhecer sente a necessidade de adaptar-se a cada situação nova relacionada à velhice (Santos, 2010).

O receio com a perda das funções físicas também é expressado no relato de Corticeira ao afirmar que com o avanço da idade, o corpo não responde como antes, para ela o sentido do envelhecimento está relacionado às limitações do corpo. Compreende-se que este sentido é produzido na corporeidade, ao envelhecer começam as dores no corpo, a perda das forças, a respiração fica curta, se percebem dificuldades para caminhar ou correr. Quando se define o envelhecimento no âmbito biológico, entende-se que acontecem mudanças morfológicas, como rugas e cabelos brancos entre outras; as alterações fisiológicas atreladas às funções orgânicas; e as bioquímicas, que envolvem as transformações das reações químicas que se processam no organismo (Santos, 2010).

Para Corticeira a saúde seria assegurada pelo fato de manter o corpo em movimento, para "ajudar na circulação do sangue", sendo que a entrevistada referiu cultivar o hábito de fazer caminhadas no campo. Também afirmou ser bastante ativa na realização das atividades de casa e cuidar dos animais, e que raramente frequenta uma academia para realizar exercícios físicos. A entrevistada, considera ainda que é preciso ter atendimento médico e de enfermagem na comunidade, além da realização de grupos com orientações sobre saúde, como por exemplo, hipertensão arterial. Outra participante relacionou o envelhecer a perda da saúde, para Goiabeira-do-mato, o sentido do envelhecimento está em não ter problemas de saúde, evitando o adoecimento. Para os cuidados com a saúde, a entrevistada referiu consultar-se com o médico, ter uma alimentação saudável e fazer caminhadas esporadicamente.

O sentido do envelhecimento para Coronilha tem relação com as complicações de saúde como ter reumatismo, a perda das forças, desgastes físicos e psicológicos como o "cansaço na memória", os golpes sofridos ao longo da vida, as dificuldades enfrentadas nos trabalhos e os aborrecimentos. Assim como as participantes anteriores, ela elenca os tratamentos médicos com o uso de medicações, os cuidados com a alimentação e caminhadas como cuidados com a saúde. Descreve ser importante "descansar a memó- ria" e a prática de artesanato que considera uma atividade de lazer como crochê, tricô, costurar e bordar. Para promoção de sua saúde, gostaria de realizar exercícios físicos como ginástica e alongamento. A entrevistada considera que no Quilombo deveria vir uma unidade móvel de saúde, e ter atendimento médico e de dentista.

Para Pitangueira o envelhecimento recebe um sentido de solidão, percebido como algo negativo, ao afirmar que quando a pessoa envelhece acaba ficando sozinha, tendo que abandonar a casa. O envelhecer inclui mudanças de âmbito social quando as relações são alteradas em função da diminuição da produtividade e, principalmente, do vigor físico e poder econômico, sendo a alteração social mais evidente em países de economia capitalista (Santos, 2010). A Comunidade Quilombola, mesmo valorizando a coletividade, não está deslocada da conjuntura socioeconômica do país, o que faz com que os mais jovens do quilombo migrem para outros municípios para a continuidade dos estudos e/ou em busca de colocações laborais. O declínio das funções físicas que propiciavam o autocuidado e a subsistência da pessoa que envelhece pode suscitar o medo da solidão e da perda da autonomia.

A conotação negativa do envelhecimento também foi expressada por Cambará, que referiu ir consultar-se com o médico como uma ação que garantiria a promoção de sua saúde. Já Pitangueira referiu como cuidado em saúde, os tratamentos médicos, através do uso de medicações, e caminhar para fazer as atividades cotidianas da casa. Para prevenção do adoecimento e promoção de saúde, a entrevistada relatou que gostaria de praticar atividades como artesanato, para isso seria necessário realizar um curso e destinar um local apropriado para sua prática na comunidade. É interessante notar, que mesmo sendo o artesanato uma atividade laboral de subsistência muito praticada nas comunidades tradicionais, as entrevistadas referem a atividade como lazer.

O sincretismo religioso aliado as benzeduras, uso de ervas e rituais presentes nos saberes religiosos enquanto práticas das comunidades tradicionais nos cuidados à saúde (Mendes, \& Cavas, 2017) não foi mencionado pelos entrevistados, mesmo sendo estas estratégias usadas amplamente nesta comunidade. Reflito sobre a dialogia evocada pelas perguntas que formulamos e os sentidos que foram produzidos a partir delas, sendo o "cuidar da sua saúde" e "as ati- 
vidades para prevenção de doenças e promoção da saúde" expressões que remetem a confluência entre os saberes tradicionais e biomédicos, estes últimos possivelmente valorados pela dificuldade ao acesso aos serviços de saúde.

Outro ponto a considerar, é que pelo difícil acesso aos dispositivos de saúde as comunidades acabam utilizando outros métodos para cuidarem da saúde, sendo alguns deles provenientes dos saberes tradicionais que por muito tempo eram mais utilizados do que os advindo do saber biomédico. Com as políticas públicas de saúde quilombola, algumas comunidades começaram a ter o acesso aos serviços de atenção à saúde, e a procura pela prática destes saberes tradicionais e religiosos diminuiu, no entanto não deixou de existir. Ainda neste aspecto, é comum que em alguns tipos de enfermidades recorrem-se às benzedeiras, mesmo após receber o diagnóstico e o tratamento médico. Pois as benzeduras podem ser entendidas como um tratamento complementar, fazendo com que a recuperação e a cura das enfermidades aconteçam de forma rápida.

\section{Envelhecer no Quilombo (Discussão)}

Através dos sentidos interpretados nas falas dos idosos nas entrevistas, dividiu-se o estudo em dois eixos temáticos, sendo eles: Os sentidos do Envelhecimento e Práticas para obtenção de Saúde.

\section{Os sentidos do envelhecimento}

O sentido do envelhecimento para o Araçá-amarelo está relacionado à idade cronológica. Para Duarte, Santana, Soares, Dias e Thofern (2005, p. 43) "a idade em si não representa o estado do envelhecimento de uma pessoa, mas a combinação de vários fatores associados". Segundo o Instituto Brasileiro de Geografia e Estatística (IBGE), a expectativa de vida no Brasil vem aumentando nos últimos anos. Em 2017, a expectativa era de 76 anos, e no Rio Grande do Sul, 78 anos. Com relação à população quilombola, o IBGE prevê que o censo de 2020 incluirá dados específicos o que permitirá maior valorização dessas comunidades e participação social no controle das políticas públicas quilombolas (FCP, 2018; IBGE, 2019).

Em países desenvolvidos, com o aumento da expectativa de vida tem-se a incorporação de uma quarta idade nos ciclos de vida, sendo incluídos a esta idade aqueles muito velhos, ou, ainda, com 80 anos ou mais (Morais, Rodrigues, \& Gerhardt, 2008). O envelhecimento pode receber outras classificações, segundo M. J. Lopes (2016), poderiam ser descritas como os "idosos jovens" as pessoas entre 60 e 74 anos, os "idosos velhos" de 75 a 84 anos e os "idosos mais velhos”, de 85 anos ou mais” (M. J. Lopes, 2016).

Estudos como o de Cardoso e Ferreira (2009) apontam uma mudança na visão negativa sobre a velhice relacionada à doença, à falta de autonomia, e à improdutividade que seriam decorrentes das perdas biológicas, funcionais, psicológicas e sociais que podem acontecer no período. Tal concepção da velhice como um processo progressivo e irreversível de degeneração vem se modificando paulatinamente, na medida em que são disponibilizados recursos que possibilitam mais qualidade de vida (Cardoso, \& Ferreira, 2009).

Apesar do aumento da população idosa nos últimos anos, o envelhecimento não significa o adoecimento desses indivíduos. Aragão (2014) descreve ser a importância da consciência de que a velhice pode trazer limitações físicas e funcionais, para que sejam elaboradas maneiras de minimizar sofrimentos físicos e psíquicos que podem ser decorrentes de tais limitações. Dentro dessa perspectiva, os grupos mais afetados seriam aqueles "grupos alijados historicamente como pobres, pardos, negros, índios e outros, em particular na saúde, enfrentam maiores dificuldades em exercer seus direitos, e este cenário é agravado com os problemas decorrentes do envelhecimento" (Aragão 2014, p. 43).

De acordo com Oliveira, Pereira, Guimarães e Caldeira (2015, p. 2879), as "comunidades quilombolas vivenciam situação de vulnerabilidade social, mesmo mais de um século da abolição da escravatura, principalmente em relação aos cuidados de saúde". Santos (2014) também defende que as desigualdades raciais ainda presentes no Brasil incidem sobre as condições de vida da população negra, o que acarreta em impactos no processo de envelhecimento das pessoas deste segmento da sociedade.

No quilombo Rincão do Couro, o envelhecimento continua sendo visto como algo negativo para parte dos idosos. Cambará e Pitangueira justificam que ao envelhecer, o idoso precisa lidar com a solidão. "Eu vejo mais negativo, por que a gente pega envelhecer [...] já tem que ir abandonando a casa [...] não vai viver sozinho, tem de procurar algum lugar melhor" (Pitangueira, 66 anos). 
De acordo com Sarmento (2014), um acontecimento de vida pode gerar consequências com grande significado no modo de viver das pessoas. Nesse aspecto, as experiências vividas no decorrer da vida, também foram relacionadas aos sentidos do envelhecimento por uma das idosas quilombolas. "Os cansaços ou golpes da vida, os trabalhos, os aborrecimentos, as complicações de saúde" (Coronilha, 74 anos).

Destaca-se a singularidade de avaliações que as pessoas podem realizar sobre os acontecimentos da vida, sendo que estas dependerão do efeito cumulativo e relação entre os eventos, menor previsibilidade ou o desejo de que aconteça, além de maior vulnerabilidade pessoal e menor habilidade para prevenir as decorrências negativas deste acontecimento; dependendo ainda do contexto de sua ocorrência (Sarmento, 2014).

O envelhecimento para duas participantes foi descrito como a perda gradativa das funções do corpo, com o avanço da idade, o corpo já não responde como antes, isso implica na redução da produtividade ao realizar as atividades diárias. Embora tenha sido levantado pelos idosos as diminuições das capacidades físicas, foi possível observar que os mesmos conseguem realizar as atividades cotidianas do dia a dia. Para Ribeiro (2011), a realização das atividades cotidianas pode atuar como o principal indicador de funcionalidade dos idosos.

O bem envelhecer foi descrito por alguns dos idosos do Quilombo Rincão do Couro como o não adoecimento do corpo. Para Santos, Silva, Martins e Martinez (2011), o conceito de saúde está além de ter um corpo saudável, livre de doenças. A saúde também dependerá das possibilidades de alimentação, habitação, educação, renda, meio ambiente, trabalho, transporte, emprego, lazer, liberdade, acesso e posse da terra e acesso a serviços de saúde; conforme as formas de organização social da produção, que também podem ocasionar em iniquidades. Santos e Silva (2014, p 1051) afirmam que para se entender as condições de saúde e os modos pelos quais as pessoas enfrentam o processo saúde-doença, é preciso analisar suas práticas; e ainda o contexto em que são desenvolvidas e (re)produzidas, segundo suas características e especificidades históricas.

\section{Práticas para a obtenção de saúde}

A promoção da saúde, para Torres, Zeni, Oliveira e Melo (2018), consiste em uma das mais importantes estratégias para se alcançar a melhoria da qualidade de vida da população. O incentivo do autocuidado em saúde e da coletividade torna um aspecto necessário para a sua promoção (Brasil, 1986); para isso, é preciso que a população tenha acesso à informação e educação em saúde. A Psicologia tem um papel fundamental através da inserção do psicólogo dentro da comunidade desenvolvendo um trabalho voltado à promoção de saúde. Rocha e Santos (2015, p. 65) apontam para a aproximação entre a Psicologia e a saúde pública, no intuito de fazer com que os psicólogos, repensem suas práticas, "deslocando sua visão do sujeito adoecido para um sujeito em movimento dentro de um dado território (enquanto espaço histórico, político, econômico e social), se reconfigurando, assim, o próprio objeto do olhar psicológico)".

Para os moradores entrevistados, um dos sentidos atribuídos aos cuidados à saúde, está relacionado com os saberes biomédicos exemplificados pela consulta médica, a realização dos tratamentos médicos indicados e o uso de medicamentos. É importante ressaltar que no quilombo não existe atendimento médico próximo, nem uma Equipe Estratégia da Família Quilombola. A ausência da atenção à saúde na localidade reforça a situação de vulnerabilidade dos quilombolas (Cardoso, Melo \& Freitas, 2018). Segundo Santos (2014), a ausência de atendimento médico adequado gera consequências como a dificuldade retirar receitas de medicamentos para tratamento contínuo e mesmo a morte por falta de assistência.

Para alguns dos idosos quilombolas, uma forma de obtenção de saúde no envelhecimento se dá através do cuidado com a alimentação. No quilombo há a produção, o cultivo e a criação de animais para subsistência; as espécies mais cultivadas são milho, feijão, batata doce, abóbora e legumes. As comunidades tradicionais, em sua maioria, caracterizam-se pelo forte vínculo com o meio ambiente, vivendo de agricultura com mão de obra familiar produzindo o básico para o consumo (Leite, Martins, Ferreira, Batista, \& Rosário, 2016).

Outra prática usual para os idosos do quilombo é a caminhada, referida como uma maneira de se prevenir doenças e de promoção de saúde. Além disso, citam a realização das atividades diárias como cuidar da casa, ir trabalhar na agricultura e, cuidar dos animais. "A gente faz empenho da caminhada, caminha, vai num vizinho [...] Eu nunca paro, tenho que está trabalhando [...] na agricultura, cuidando os animais [...] roçar, capinar, lavrar, amansar bois, amansar vacas para tirar leite, picar lenha" (Araçá-amarelo, 83 anos). 
Segundo os idosos no quilombo Rincão do Couro deveria ter uma unidade móvel de atendimento em saúde, com uma equipe composta por médico, dentista, e enfermagem com grupos de orientações sobre saúde para a comunidade quilombola dessa localidade. A partir de 2004, algumas Comunidades Quilombolas de diversas regiões do Brasil passaram ter acesso a política de inclusão na Atenção Básica de Saúde (ABS) por meio a Portaria no 1.434 do Ministério da Saúde, que disponibiliza um incentivo financeiro para os municípios levando em consideração "a dificuldade de acesso das populações quilombolas às ações e aos serviços de saúde, por suas características sociais" na criação de equipe de ESF, para atuarem nas Comunidades Quilombolas.

Neste mesmo ano o governo federal, numa ação coordenada pela Secretaria de Políticas de Promoção da Igualdade Racial (SEPPIR), lançou o Programa Brasil Quilombola com objetivo de promover "o acesso ao conjunto de bens e serviços sociais necessários ao seu desenvolvimento das CRQ, considerando sempre a realidade sociocultural destas comunidades". Levando em conta a precariedade em que vivem os quilombolas, o programa destaca a necessidade e o desenvolvimento de ações específicas que garantam o bem-estar físico, psicológico e social, e a qualidade do sistema de saúde. Buscando a prevenção, promoção e recuperação da saúde da família quilombola de forma integral e contínua (Seppir, 2004, p. 5).

O Departamento de Atenção Básica da Secretaria de Atenção à Saúde do Ministério da Saúde, publicou em 17 de janeiro de 2008, a Portaria n ${ }^{\circ}$ 90/GM de forma a beneficiar com recursos financeiros federais, os municípios que implantarem equipes de Saúde da Família e equipe de Saúde Bucal para atuar nas comunidades em seu território. O repasse é $50 \%$ superior para municípios com presença de quilombolas e assentados (Seppir, 2013). Vale ressaltar que no anexo da Portaria no 90/GM estão contemplados 774 municípios, sendo um deles o município de Piratini, onde está localizado o Quilombo Rincão do Couro. Além das demandas em saúde, surgiu também a necessidade oferta de cursos para a comunidade quilombola, bem como a aprovação de mais projetos que beneficiem o quilombo Rincão do Couro.

Segundo Silva (2015) percebe-se que mesmo com existência do programa que engloba o acesso a várias políticas, nem todas as $\mathrm{CRQ}$, são contempladas. No que se refere a saúde quilombola, existe uma "alta prevalência de problemas básicos de saúde ligados às precárias condições de vida e moradia, à ausência de saneamento básico e ao acesso restrito à educação e serviços de saúde" nas comunidades. A falta de "serviços de saúde" aliada "a condição histórica de exclusão social" dessa parcela da sociedade os coloca numa situação de "vulnerabilidade, favorecendo a instalação de diversos agravos à saúde" (pp. 27-28).

Por outro lado, as Comunidades que já contam com profissionais da ESF, estudos realizados apontam que quanto mais próximo estiver o "trabalhador em saúde da cultura de uma população [...]", melhor seráa compreensão do profissional em relação "[...] a forma como as pessoas sentem e vivem a sua saúde” (Silveira, Chagas, Hora, Daher, Acioli, 2015, p. 623). Importante ressaltar que se deve considerar as especificidades $\mathrm{e}$ necessidades de cada Quilombo, respeitando suas características e atender as demandas de acordo com a dinâmica da comunidade. Para Silveira et al. (2015, p. 623), "refletir sobre os aspectos singulares de uma população quilombola torna-se imprescindível para um cuidado singular, de qualidade e resolutivo pela equipe de saúde da família."

O estado do "RS é pioneiro em cofinanciamento e na criação do incentivo para as ESF e equipes de Saúde Bucal (ESB)". Então no ano de 2013, o estado estabelece por meio a Portaria no 539/13 da SES/RS o incentivo financeiro estadual para ESF, ESB e ESFQ (Moscardini, 2015, pp. 20.21). Alves (2014) como citado em na SES/RS (2014) o estado é considerado referência na implantação da Política de Saúde da População Negra, sendo exemplificada pela implementação da ESFQ, presente em 46 Comunidades Quilombolas de 39 municípios (Duarte, 2014).

Sendo um deles Capivari do Sul, com o projeto de Lei no 25/2018 que autoriza a abertura de crédito adicional para a execução do Plano de Trabalho do Projeto Cuidando da Saúde Quilombola: prevenção e ações terapêuticas no Quilombo Costa da Lagoa, juntamente com a equipe de ESF. Tendo como objetivo "potencializar a troca de diálogos e compartilhamento de experiências e melhoria na adaptação do modo de vida individual e coletivo". Já as ações terapêuticas têm a finalidade de proporcionar "algumas vantagens, como melhora nas relações sociais, nos níveis de conhecimento sobre questões discutidas na capacidade para lidar com situações inerentes ao transtorno sofrido, ou na confiança e alívio emocional" (Prefeitura Municipal de Capivari, 2018, pp. 2- 8). 
No entanto, na minha percepção com base na busca de material para embasar o estudo, foi possível observar que nem todos os municípios do RS acessam essa política seja, do governo federal ou estadual. Precisaria de um estudo mais aprofundado na tentativa de identificar as causas ou impedimentos para que os municípios não acessem essa política, ou se os mesmos têm acesso, por que não vêm sendo executado. Neste caso em específico o município de Piratini, atendendo uma demanda antiga das Comunidades Quilombolas.

Os moradores destas Comunidades, quando necessitam de atendimento no SUS precisam se deslocarem até Pronto Atendimento (PA) na cidade. Outro meio utilizado pelos quilombolas do Rincão do Couro, é o deslocamento da Comunidade no dia anterior a busca por atendimento nas UBS, que ficam também localizadas na sede do município. A ausência de ações públicas voltadas para a saúde dos moradores desta comunidade, e a falta de equipes de atendimento, assim como a dificuldade de transporte e deslocamento até a cidade ficam evidentes na fala de cada participante do estudo.

\section{Anotações de uma psicóloga quilombola (Considerações finais)}

Os resultados obtidos no estudo partiram de minhas longas caminhadas entre as árvores, no bosque quilombola em Rincão do Couro. As reflexões possibilitaram a descrição dos sentidos do envelhecimento para os idosos quilombolas, como também a identificação de ações e estratégias usadas pelos idosos no cuidado e prevenção de doenças e na promoção à saúde no Quilombo. O envelhecimento foi relacionado à idade cronológica, à solidão, as mudanças do corpo, ao adoecimento e aos acontecimentos da vida - aos cansaços e golpes da vida, entendidos aqui como acontecimentos que ganham historicidade e ancestralidade. As ações de promoção à saúde foram descritas como sendo as atividades do cotidiano na comunidade presentes nos saberes tradicionais compartilhados, sendo endossadas por diversos estudos como estratégias preconizadas para o envelheci- mento saudável. Os saberes biomédicos foram elencados nos cuidados à saúde com evocação a consulta médica, prescrições e tratamentos. O estudo apontou que parte dos idosos sentem a necessidade de haver uma equipe de saúde no Quilombo sem precisarem se deslocarem até a distante sede do município em busca desse atendimento.

Pensar a Psicologia hoje é também refletir sobre a importância do trabalho da psicóloga junto às comunidades quilombolas, com a finalidade de criar estratégias de cuidado, prevenção e promoção à saúde que sejam adequadas a pluralidade cultural dos quilombos. Como também conhecer e identificar as dificuldades e inquietações da comunidade, desenvolvendo atividades que visem uma melhor qualidade de vida $\mathrm{e}$ um envelhecimento saudável. O resultado desta pesquisa indica um novo ponto de partida para as pesquisadoras, na perspectiva de buscar intervenções que possam atender algumas dessas demandas, e possibilitar que a Comunidade tenha conhecimento dos direitos sociais adquiridos nos últimos anos que são desconhecidos para a maioria.

Para mim, enquanto mulher negra psicóloga quilombola e pesquisadora, o estudo me possibilitou estar novamente em contato direto com o quilombo vivendo essa experiência e fortalecendo os vínculos com a Comunidade. Isso porque enquanto estudante quilombola, fiquei ao longo da minha formação afastada da comunidade. Foram cinco anos de discussão na universidade pública tecendo reflexões e agora enquanto quilombola e psicóloga. Isso me permitiu um conhecimento aprofundado, através da literatura, sobre outros contextos quilombolas pelo Brasil, que, mesmo distantes geograficamente, possuem culturas e necessidades semelhantes. Também me possibilitou o acesso as leis que asseguram alguns direitos das Comunidades Quilombolas. Por fim, destaco a necessidade de se elaborar mais estudos em Psicologia sobre comunidades tradicionais, em especial, as Comunidades Quilombolas no intuito de explorar a historicidade, vivências, costumes e saberes culturais dos povos de quilombos.

\section{Referências}

Aragão, J. A. (2014). Acesso de saúde na atenção básica prestada aos quilombolas, Piauí (Tese de doutorado). Pontifícia Universidade Católica do Rio Grande do Sul, Porto Alegre, RS. Recuperado de http://tede2.pucrs.br/tede2/ handle/tede/6631

Bennett, M. (2010). Os quilombolas e a resistência. Revista Palmares, Cultura Afro-Brasileira, 6(6), 28-35. 
Lopes, E. D. S.; Paixão, C. F. e Santos, D. B. (2019). “Os Cansaços e Golpes da Vida”.

Brasil. Ministério da Saúde. (1986). Relatório final. Trabalho apresentado na Conferência Nacional de Saúde, Brasília, DF, 8. Recuperado de http://bvsms.saude.gov.br/bvs/publicacoes/8_conferencia_nacional_saude_relatorio_final.pdf

Brasil. Ministério da Saúde. (2010) Atenção à saúde da pessoa idosa e envelhecimento (Textos básicos de saúde série pactos pela saúde 2006, Vol. 12). Brasília, DF: o autor. Recuperado de http://bvsms.saude.gov.br/bvs/publicacoes/atencao_saude_pessoa_idosa_envelhecimento_v12.pdf

Brito, M. C. C., Freitas, C. A. S. L., Mesquita, K. O., \& Lima, G. K. (2013). Envelhecimento populacional e os desafios para a saúde pública: Análise da produção científica. Revista Kairós Gerontologia, 16(2), 161-178.

Cardoso, C. S., Melo, L. O., \& Freitas, D. A. (2018). Condições de saúde nas comunidades quilombolas. Revista de Enfermagem UFPE, 12(4), 1037-1045. https://doi.org/10.5205/1981-8963-v12i4a110258p1037-1045-2018

Cardoso, M. C. S., \& Ferreira, M. C. (2009). Envolvimento religioso e bem-estar subjetivo em idosos. Psicologia Ciência e Profissão, 29(2), 380-393. https://doi.org/10.1590/S1414-98932009000200013

Carvalho. A. V., \& Macedo. J. P. (2018). Povos e comunidades tradicionais: Revisão sistemática da produção de conhecimento em psicologia. Revista Psicologia: Teoria e Prática, 20(3), 180-197. https://doi.org/10.5935/19806906/psicologia.v20n3p198-215

Centro de Apoio ao Pequeno Agricultor - CAPA. (2010). Comunidades quilombolas. Pelotas, RS: o autor. Recuperado de http://www.capa.org.br/digishop/revelando-os-quilombos-no-sul/

Conselho Regional de Psicologia do Rio Grande do Sul - CRP-RS. (2018). Encontro preparatório da rede de articulação psicologia, povos indígenas, quilombolas, de terreiro, tradicionais e em luta por território. Porto Alegre, RS: o autor. Recuperado de http://www.crprs.org.br/comunicacao/noticias/evento-sobre-indigenas-quilombolas-reune-dezenas-de-pessoas-no-crprs-4169

Costa, E. M. S. (1998). Conceito etimológico e significados da palavra "velho" e similares. In: E. M. S. Costa, Gerontodrama: A velhice em cena: Estudos clínicos e psicodramáticos sobre o envelhecimento e a terceira idade (2 ed., pp. 13-48). São Paulo, SP: Agora.

Decreto No 4.887, de 20 de novembro de 2003. Regulamenta o procedimento para identificação, reconhecimento, delimitação, demarcação e titulação das terras ocupadas por remanescentes das comunidades dos quilombos de que trata o art. 68 das disposições constitucionais transitórias. Diário Oficial União, 21 set 2003.

Duarte, N. (2014). Encontro apresenta experiências de promoção de saúde mental junto a comunidades quilombolas. Porto Alegre, RS: Secretaria Estadual da Saúde do Rio Grande do Sul. Recuperado em https://estado.rs.gov. br/encontro-apresenta-experiencias-de-promocao-de-saude-mental-junto-a-comunidades-quilombolas

Duarte, V. B., Santana, M. G., Soares, M. C., Dias, D. G., \& Thofern, M. B. (2005). A perspectiva do envelhecer para o ser idoso e sua família. Revista Família Saúde e Desenvolvimento, 7(1), 42-50. https://doi.org/10.5380/ fsd.v7i1.8052

Flick, U. (2013). Introdução à metodologia de pesquisa: Um guia para iniciantes (U. Flick, \& M. Lopes, Trad.). Porto Alegre, RS: Penso.

Fundação Cultural Palmares - FCP. (2019). Comunidades certificadas. Brasília, DF: o autor. Recuperado de http://www.palmares.gov.br/?page_id=37551

Gentini, A. G. M. (2016). Abrindo portas, acolhendo culturas, construindo perspectivas: Notas sobre o ingresso de alunos indígenas e quilombolas na universidade. In:V. A. Pereira, S. N. Schirmer, \& D. B. Jardim (Orgs.), A política de ações afirmativas na FURG: Um espaço de formação permanente (2a ed., pp. 73-80). Rio Grande, RS: Universidade Federal do Rio Grande.

Gonçalves, B. S., \& Fernandes, S. L. (2017). Reflexões sobre atuação da psicologia com populações indígenas, quilombolas e povos tradicionais: Descolonização e encontro de saberes. Anais do Encontro Nacional da Associação Brasileira de Psicologia Social, Uberlândia, MG, Brasil, 19.

Instituto Brasileiro de Geografia e Estatística - IBGE. (2018). Tábua completa de mortalidade para o Brasil 2017: Breve análise da evolução da mortalidade no Brasil. Brasília, DF: o autor. Recuperado de https:/ /biblioteca.ibge. gov.br/index.php/biblioteca-catalogo?view=detalhes\&id=2101628

Lei No 10.741 , de 1 de outubro de 2003. Dispõe sobre o estatuto do idoso e dá outras providências. Diário Oficial União, 3 out 2003. 
Leite, D., Martins, A. L., Ferreira, J., Batista, K. N., \& Rosário, M. J. (2016). Racismo, saúde e comunidades remanescentes de quilombos: Reflexões da fisioterapia. Revista Conexões de Saberes, 1(1), 111-116. https://doi. org/10.18542/cs.vli1.3915

Lopes, E. D. S. (2016a). A cultura do quilombo rincão do couro representadas por benzedeiras e o dom do benzer. Anais do Colóquio Internacional de Povos e Comunidades Tradicionais: Estado, capital e territórios tradicionais: Dinâmicas territoriais em disputa. Montes Claros, MG, Brasil, 4.

Nascentes, M.S., Silva, R.S., Soares, R.M., Pinto, A.S., Westphal, E.P., Lopes, E. (2016). Ações afirmativas na perspectiva de estudantes quilombolas da FURG. In:V. A. Pereira, S. N. Schirmer, \& D. B. Jardim (Orgs.), A política de ações afirmativas na FURG: Um espaço de formação permanente (2a ed., pp. 199-208). Rio Grande, RS: Universidade Federal do Rio Grande.

Lopes, M. J. (2016). O envelhecimento e a qualidade de vida: A influência das experiências individuais. Revista Kairós Gerontologia, 19(2), 181-199.

Mendes, D. S., \& Cavas, C. S. T. (2017). Benzedeiras e benzedeiros quilombolas: Construindo identidades culturais. Interações (Campo Grande), 19(1), 3-14. https://doi.org/10.20435/inter.v19i1.1568

Morais, E. P., Rodrigues, R. A., \& Gerhardt, T. E. (2007). Os idosos mais velhos no meio rural: Realidade de vida e saúde de uma população do interior gaúcho. Texto Contexto Enfermagem, 17(2), 374-383. https://doi.org/10.1590/ S0104-07072008000200021

Moreira, V., \& Nogueira, F. N. N. (2008). Do indesejável ao inevitável: A experiência vivida do estigma de envelhecer na contemporaneidade. Psicologia USP, 19(1), 59-79. https://doi.org/10.1590/S0103-65642008000100009

Moscardini, A. S. (2015). Incentivos financeiros estaduais à saúde da família: Análise da distribuição nas 30 regiões de saúde, RS 2013-2014 (Trabalho de conclusão). Universidade Federal do Rio Grande do Sul, Porto Alegre, RS.

Oliveira, S. K. M., Pereira, M. M., Guimaraes, A. L. S., \& Caldeira, A. P. (2015). Autopercepção de saúde em quilombolas do norte de Minas Gerais, Brasil. Revista Ciência \& Saúde Coletiva, 20(9), 2879-2890.

Portaria No 59, de 27 de abril de 2010. Registrar no Livro de Cadastro Geral n. ${ }^{\circ} 12$ e certificar que, conforme as declarações de Autodefinição e os processos em tramitação nesta Fundação Cultural Palmares, as Comunidades a seguir, se autodefinem como remanescentes de Quilombo. Diário Oficial União, 28 abr 2010.

Portaria No 90, de 17 de janeiro de 2008. Atualiza o quantitativo populacional de residentes em assentamentos da reforma agrária e de remanescentes de quilombos, por município, para cálculo do teto de Equipes Saúde da Família, modalidade I, e de Equipes de Saúde Bucal da estratégia Saúde da Família. Diário Oficial União, 18 jan 2008.

Portaria No 1.434, de 14 de julho de 2004. Define mudanças no financiamento da atenção básica em saúde no âmbito da estratégia Saúde da Família, e dá outras providências. Diário Oficial União, 14 jul 2004.

Prefeitura Municipal de Capivari do Sul. (2018). Projeto Cuidando da Saúde Quilombola: Prevenção e ações terapêuticas. Capivari do Sul, RS: o autor. Recuperado de: https://www.camaracapivaridosul.rs.gov.br/folder-projetos/PROJETOS\%20APROVADOS\%202018/PLE\%2025.2018.pdf

Projeto de Lei No 25/2018, de 29 de março de 2018. Autoriza a abertura de crédito adicional especial no valor de R\$ 32.000,00 (trinta e dois mil reais). Diário Oficial Municipal de Capivari do Sul, 30 mar 2018.

Rey, G. (2002). Pesquisa qualitativa em psicologia: Caminhos e desafios (M. A. F. Silva, Trad.), São Paulo, SP: Pioneira-Thomson Learning.

Resolução No 466, de 12 de dezembro de 2012. A presente resolução incorpora, sob a ótica do indivíduo e das coletividades, referenciais da bioética, tais como, autonomia, não maleficência, beneficência, justiça e equidade, dentre outros, e visa a assegurar os direitos e deveres que dizem respeito aos participantes da pesquisa, à comunidade científica e ao Estado. Diário Oficial da União, 13 dez 2012.

Ribeiro, L H. M. (2011). Relações entre exercícios físicos, força muscular e atividades de vida diária em mulheres idosas recrutadas na comunidade (Dissertação de mestrado). Universidade Estadual de Campinas, Campinas, SP. Recuperado de http://repositorio.unicamp.br/bitstream/REPOSIP/308243/1/Ribeiro_LucianaHelenaMartins_M.pdf

Rocha, R. V., \& Santos, L. A. (2015). Psicologia e promoção da saúde: Fortalecimento dos direitos humanos em comunidades tradicionais. Revista Brasileira de Psicologia, 2, 61-72. 
Lopes, E. D. S.; Paixão, C. F. e Santos, D. B. (2019). "Os Cansaços e Golpes da Vida”.

Santos, R. C., Silva, M. S., Martins, S. S., \& Martinez, J. F. N. (2011). Práticas e saberes de saúde em comunidades remanescentes de quilombos no estado de Goiás. In: Anais do Congresso Brasileiro de Ciências do Esporte, Porto Alegre, RS, 17. Recuperado de http://congressos.cbce.org.br/index.php/conbrace2011/2011/paper/view/3215/1328

Santos, R. C., \& Silva, M. S. (2014). Condições de vida e itinerários terapêuticos de quilombolas de Goiás. Revista Saúde e Sociedade, 23(3), 1049-1063. https://doi.org/10.1590/S0104-12902014000300025

Santos, S. S. C. (2010). Concepções teórico-filosóficas sobre envelhecimento, velhice, idoso e enfermagem gerontogeriátrica. Revista Brasileira de Enfermagem, 63(6), 1035-1039. Brasília, DF. https://doi.org/10.1590/S003471672010000600025

Santos, V. C. (2014). Qualidade de vida e fatores associados entre idosos quilombolas (Dissertação de mestrado). Universidade Estadual do Sudoeste da Bahia, Jequié, BA. Recuperado de http://www2.uesb.br/ppg/ppges/wp-content/uploads/2017/03/vanessa-DISSERTAC387C383O-VersC3A3o-finall.pdf

Sarmento, M. A. R. (2014). Experiências de vida e sabedoria na pessoa idosa (Dissertação de mestrado). Faculdade de Educação e Psicologia, Universidade Católica Portuguesa, Porto, Portugal. Recuperado de https://repositorio. ucp.pt/bitstream/10400.14/17304/1/Disserta\%C3\%A7\%C3\%A3o_Mestrado_2014.pdf

Secretaria Especial de Políticas de Promoção da Igualdade Racial - Seppir. (2004). Programa Brasil quilombola. Brasília, DF: o autor.

Secretaria de Políticas Públicas de Promoção da Igualdade Racial - Seppir. (2013). Guia de políticas públicas para comunidades quilombolas. Brasília, DF: o autor.

Silva, M. H. P. (2015). Assistência à saúde em comunidades quilombolas: Revisão sistemática (Monografia de graduação). Universidade Federal da Bahia, Salvador, BA. Recuperado de https://repositorio.ufba.br/ri/handle/ $\mathrm{ri} / 18346$

Silva, L. R. F. (2008). Terceira idade: Nova identidade, reinvenção da velhice ou experiência geracional? Physis: Revista de Saúde Coletiva, 18(4), 801-815. https:// doi.org/10.1590/S0103-73312008000400011

Silveira, D. B., Chagas, M. D. F., Hora, T. S., Daher, D. V., \& Acioli, S. (2015). Implicações da cultura no cuidado de equipe de saúde da família em uma comunidade quilombola. Revista de Enfermagem da UERJ, 23(5), 622-626. https:// doi.org/10.12957/reuerj.2015.17734

Spink, M. J. P. (2011). Psicologia social e saúde: Práticas, saberes e sentidos (8a ed.). Petrópolis, RJ: Vozes.

Spink, M. J., \& Lima, H. (2013). Rigor e visibilidade: A explicitação dos passos da interpretação. In: M. J. P. Spink, Práticas discursivas e produção de sentidos no cotidiano: Aproximações teóricas e metodológicas (pp. 93-122). Rio de Janeiro, RJ: Cortez.

Spink, M. J. P., \& Medrado, B. (2013). Produção de sentido no cotidiano: Uma abordagem teórico-metodológica para análise das práticas discursivas. In: M. J. P. Spink, Práticas discursivas e produção de sentidos no cotidiano: Aproximações teóricas e metodológicas (pp. 41-62). Rio de Janeiro, RJ: Cortez.

Spink, M. J. P., \& Menegon, V. M. (2013). A pesquisa como prática discursiva: Superando os horrores metodológicos. In: M. J. P. Spink, Práticas discursivas e produção de sentidos no cotidiano: Aproximações teóricas e metodológicas (pp. 63-92). Rio de Janeiro, RJ: Cortez.

Takahashi, F. G. M., \& Alves, V. P. (2015). Imagens representacionais das políticas públicas à educação e à saúde, no imaginário de um grupo de idosos da comunidade Quilombola-Kalunga, de Monte Alegre de Goiás. Ensaio: Avaliação e Políticas Públicas em Educação, 23(88), 567-592. https://doi.org/10.1590/S010440362015000300002

Torres, R. C., Zeni, P. F., Oliveira, C. C. C., \& Melo. C. M. (2018). A importância do autocuidado para a manutenção da saúde em comunidade quilombola de Sergipe. Scientia Plena, 14(1), 1-9. https://doi.org/10.14808/sci. plena.2018.017501

\section{Elisângela Domingues Severo Lopes}

Psicóloga pela Universidade Federal do Rio Grande (FURG), Rio Grande - RS. Brasil.

https://orcid.org/0000-0003-4355-564X

E-mail: elisangelasevero.lopes@gmail.com 


\section{Cassiane de Freitas Paixão}

Professora associada da Universidade Federal do Rio Grande (FURG), Rio Grande - RS. Brasil. Mestre em Sociologia pela Universidade Federal do Rio Grande do Sul (UFRGS), Porto Alegre - RS. Brasil. Doutora em Educação pela Universidade do Vale dos Sinos (Unisinos), São Leopoldo - RS. Brasil.

D https://orcid.org/0000-0002-8085-1862

E-mail: cassianepaixao@outlook.com

\section{Daniela Barsotti Santos}

Psicóloga pela Universidade Estadual Paulista Júlio de Mesquita Neto (Unesp), Assis - SP. Brasil. Doutora em Enfermagem pela USP. Professora Adjunta da Universidade Federal do Rio Grande, Psicóloga pela Universidade Estadual Paulista Júlio de Mesquita Neto (Unesp), Assis - SP. Brasil. Mestre em Psicologia pela Universidade de São Paulo (USP), Ribeirão Preto - SP. Brasil. Doutora em Enfermagem pela USP, Ribeirão Preto- SP. Brasil.

(iD) https://orcid.org/0000-0002-6154-4525

E-mail: danibarsotti@gmail.com

Endereço para envio de correspondência:

Curso de Psicologia Instituto de Ciências Humanas e da Informação, Universidade Federal do Rio Grande Campus Carreiros, Av. Itália, KM 8, CEP: 96.201-900, Rio Grande, RS. Brasil.

Recebido 09/04/2019

Aceito 06/05/2019

Received 04/09/2019

Approved 05/06/2019

Recibido 09/04/2019

Aceptado 06/05/2019

Como citar: Lopes, E. D. S., Paixão, C. F., \& Santos, D. B. (2019). “Os cansaços e golpes da vida”: Os sentidos do envelhecimento e demandas em saúde entre idosos do quilombo Rincão do Couro, Rio Grande do Sul. Psicologia: Ciência e Profissão, 39(n.spe)., 85-100. https:// doi.org/10.1590/1982-3703003222518

How to cite: Lopes, E. D. S., Paixão, C. F., \& Santos, D. B. (2019). “The tiredness and blows of life”: The meanings of aging and health demands among elderly in quilombo Rincão do Couro, Rio Grande do Sul. Psicologia: Ciência e Profissão, 39(n.spe)., 85-100. https://doi.org/10.1590/1982-3703003222518

Cómo citar: Lopes, E. D. S., Paixão, C. F., \& Santos, D. B. (2019). “Los cansancios y golpes de la vida”: Los sentidos del envejecimiento y demandas en salud entre ancianos del quilombo Rincão do Couro, Rio Grande do Sul. Psicologia: Ciência e Profissão, 39(n.spe)., 85-100. https://doi.org/10.1590/1982-3703003222518 